\title{
The Impact of Financial Development and Technological Innovation on the Upgrading of Zhanjiang's Industrial Structure
}

\author{
Wenjie Yang ${ }^{1}$, Li Sun ${ }^{2, *}$ \\ ${ }^{1}$ School of Business, Guangdong Coastal Economic Belt Development Research Center of Lingnan Normal University, Zhanjiang, China \\ ${ }^{2}$ School of Economic and Management, Guangdong University of Petrochemical Technology, Maoming, China
}

Email address:

842841395@qq.com (Wenjie Yang),sgyjg@163.com (Li Sun)

*Corresponding author

To cite this article:

Wenjie Yang, Li Sun. The Impact of Financial Development and Technological Innovation on the Upgrading of Zhanjiang's Industrial Structure. Science, Technology \& Public Policy. Vol. 4, No. 2, 2020, pp. 69-75. doi: 10.11648/j.stpp.20200402.14

Received: July 23, 2020; Accepted: August 5, 2020; Published: August 18, 2020

\begin{abstract}
In the process of transformation and upgrading of China's industrial structure, financial development and technological innovation have played an extremely important role. Financial development is the core of the modern economy and penetrates the entire process of industrial development. It plays a pivotal role in optimizing resource allocation, providing external financial support and risk management for industries, promoting technological innovation and promoting industrial structure upgrades. On the other hand, technological innovation is the embodiment of scientific progress and the key to upgrading industrial structure. Technological innovation is the endogenous driving force of modern economic growth, speeding up the flow of resources between industries, improving production efficiency, and truly realizing the upgrading of industrial structure. Therefore, this study uses a time series model to explore the impact of financial development and technological innovation on the optimization and upgrading of Zhanjiang's industrial structure. The empirical results show that: The bank-based financial system has no Granger causality and has no positive impact on the optimization of Zhanjiang's industrial structure. But technological innovation can drive the optimization and upgrading of Zhanjiang's industrial structure. Therefore, Zhanjiang City needs to realize the integrated development of financial development and technological innovation to further promote the effective upgrading of the industrial structure.
\end{abstract}

Keywords: Financial Development, Technological Innovation, Industrial Structure Upgrading

\section{Introduction}

Technological innovation is the embodiment of scientific progress and the key to upgrading industrial structure. [1]. In the process of transformation and upgrading of China's industrial structure, financial development and technological innovation have played an extremely important role. Financial development is the core of the modern economy and penetrates the entire process of industrial development. It plays a pivotal role in optimizing resource allocation, providing external financial support and risk management for industries, promoting technological innovation and promoting industrial structure upgrades. Therefore, to analyze the coordinated development relationship between financial development, technological innovation and industrial structure upgrade from both theoretical and empirical aspects it is not only the practical need to formulate a scientific and reasonable financial development strategy and the strategy of rejuvenating the country through science and education, but also the key to promoting the adjustment and upgrading of industrial structure and achieving sustainable economic development [2].

As one of the first 14 coastal open cities in China, Zhanjiang targeted aquatic products, fruits and animal husbandry at the beginning of the reform and opening up, positioning itself in the construction of the back garden in the Pearl River Delta region and vigorously developing agricultural and sideline industries. However, compared with the development of other cities, Zhanjiang's industrialization and urbanization process is lagging behind. Table 1 shows the GDP ratio of the three major 
industries in Zhanjiang from 2000 to 2018.

Table 1. The ratio of total output value of the three major industries to GDP.

\begin{tabular}{llll}
\hline years & $\begin{array}{l}\text { Primary } \\
\text { industry ratio }\end{array}$ & $\begin{array}{l}\text { Secondary industry } \\
\text { ratio }\end{array}$ & $\begin{array}{l}\text { Tertiary } \\
\text { industry ratio }\end{array}$ \\
\hline 2000 & 0.268 & 0.374 & 0.357 \\
2001 & 0.264 & 0.370 & 0.313 \\
2002 & 0.250 & 0.433 & 0.371 \\
2003 & 0.229 & 0.458 & 0.388 \\
2004 & 0.225 & 0.489 & 0.386 \\
2005 & 0.235 & 0.438 & 0.328 \\
2006 & 0.228 & 0.452 & 0.322 \\
2007 & 0.191 & 0.457 & 0.316 \\
2008 & 0.209 & 0.452 & 0.291 \\
2009 & 0.206 & 0.431 & 0.361 \\
2010 & 0.202 & 0.405 & 0.388 \\
2011 & 0.197 & 0.408 & 0.401 \\
2012 & 0.201 & 0.377 & 0.423 \\
2013 & 0.187 & 0.396 & 0.416 \\
2014 & 0.180 & 0.397 & 0.415 \\
2015 & 0.180 & 0.383 & 0.428 \\
2016 & 0.180 & 0.382 & 0.427 \\
2017 & 0.174 & 0.377 & 0.447 \\
2018 & 0.177 & 0.361 & 0.461 \\
\hline
\end{tabular}

At present, Zhanjiang is taking on the mission of "building a provincial sub-central city and creating an important development pole for a modern coastal economic belt". Zhanjiang City is facing a huge development opportunity. This research analyzes the causal relationship between Zhanjiang's financial development and technological innovation on the upgrading of industrial structure, explores the key elements of economic growth, optimizes the industrial structure, improves the balance and inclusiveness of development.

\section{Research Theory}

As one of the earliest and most influential theories to study financial development issues, financial structure theory is founded by Yale University professor Goldsmith. Goldsmith put forward a series of indicators to measure the financial structure, in order to show the internal laws of financial structure changes. The most important indicator is the financial interrelations ratio, or FIR for short, which is the ratio of existing financial assets to national wealth, reflecting the relationship between a country's financial superstructure and the actual economic superstructure. Many scholars have made relevant research on the impact of financial development on economic growth:

Thangavelu and Jiunn explored the dynamic relationship between financial development and economic growth in Australia using co-integration and causal analysis of VAR models of time series data under a bank basic financial structure [3]. The results show that: 1. There is a two-way causal relationship between bank-based financial development and economic growth. 2. The interest rate factor in the research model does not affect the empirical results.

Shah and Bhutta believe that bank-based theory explains that commercial banks play an important role by optimizing resources and reducing risks in economic development. [4]
Demir and Hall attempted to analyze the impact of the country's financial structure on economic growth from a new structuralist perspective. Among them, the bank basic theory believes that the banking system emphasizes the positive impact of banks on the economy through three main channels. First, banks obtain information about managers and companies to improve corporate governance efficiency and improve capital allocation. Second, banks manage intertemporal, cross-sectoral and liquidity risks, thereby improving investment efficiency and promoting economic growth. Finally, banks provide funding to benefit from economies of scale [5].

On the other hand, many scholars have discussed the impact of technological innovation on economic growth:

Hong examines the Granger causality between R\&D investment and economic growth in the Korean ICT (information and communication technology) industry. There is a two-way Granger causality between ICT R\&D investment and economic growth, which indicates that ICT R\&D investment is driven by economic growth and vice versa [6].

Pradhan, Arvin and Bahmani used panel unit root and panel cointegration tests to determine the interaction between innovation, financial development, and economic growth in 49 European countries from 1961 to 2014. The results show that there is a cointegration relationship between the three series. The vector error correction model is estimated, indicating that in the long run, financial development and technological innovation are both incentives for economic growth. Therefore, policies that focus on financial development and technological innovation are a way to improve the economic performance of these countries [7].

Grant and Yeo investigated the impact of technology investment (ie technology investment), information and communication technology (ICT), and financial factors on manufacturing and service industry performance in the global manufacturing and service industry between 2006 and 2014 . The results show that as the level of technological progress increases, technology investment becomes increasingly important and contributes to economic growth [8].

Xiongfeng used annual time series data from 1976 to 2014. This study attempts to test the causal relationship between Bangladesh's financial development, trade openness, technological innovation and energy intensity during the same period. Empirical evidence shows that financial development, trade opening and technological innovation will affect economic growth [9].

In summary, it can be seen that most scholars are discussing the impact of individual factors on economic growth, and rarely discuss financial development, technological innovation, and industrial structure optimization. Therefore, this study combines the three factors, explores the interrelationships among them, finds the key elements of financial and industrial structure optimization, improves the balance and inclusiveness of development, and gives full play to the role of market mechanisms to further release market vitality to scientifically control risks and achieve economic transformation and upgrading of Zhanjiang City under the new normal and sustainable economic development. 


\section{Methodology}

\subsection{Data}

The data for this study comes from the Guangdong Provincial Statistics Bureau and Zhanjiang Statistical Yearbook. The research object is the financial institutions and industrial structure of Zhanjiang City. The research sample is from 2000 to 2018 , with each year's data as the research interval. 3.2. Research design.

\subsection{Research Design}

\subsubsection{Dependent Variable}

Industrial structure upgrading (ISU)

In order to measure the upgrading of the industrial structure, most studies are based on Clark's theorem, which uses the ratio of non-agricultural output value to total output value to measure the advanced industrial structure.

However, according to the development situation and experience of developed countries or regions, the service structure of industrial structure is a manifestation of industrial structure upgrade. Therefore, this study draws on Qian and Zheng, Liu, Yu, Cao and Zhang and other scholars used the ratio of the output value of the tertiary industry to the output value of the second industry to measure the advanced industrial structure [10-13].

The calculation formula is expressed as follows:

$$
\mathrm{ISU}_{\mathrm{jt}}=\mathrm{Y}_{\mathrm{j} 3 \mathrm{t}} / \mathrm{Y}_{\mathrm{j} 2 \mathrm{t}}
$$

\subsubsection{Independent Variable}

\section{(1) Commercial Bank Asset Ratio (BANK)}

King and Levine proposed that banks play an important role in the financial system [14]. In the financial system, banks have more significant advantages in the initial stage of economic growth. A sound banking system can make it easier for companies to obtain medium and long-term bank loans and external financing, supervise the investment decisions of corporate managers, and provide risk management. The bank-based financial system converts savings into investment and allocates resources, so capital can expand and accumulate rapidly. Commercial bank assets can effectively protect the daily normal operation of the bank, buffer risks and provide funds for the expansion of the bank and the development and development of new business and plans. Therefore, many scholars choose commercial bank asset ratio as an index to measure financial depth.

The calculation formula is expressed as follows:

$$
\text { BANK }=\text { commercial bank assets/GDP }
$$

(2) Financial interrelations ratio (FIR)

Financial tools are developing day by day and constantly innovating. In order to clarify how financial institutions, financial transaction flows, and the stock of financial instruments interact to form and promote financial development, Goldsmith identified the main economic influencing factors, namely the financial interrelations ratio. FIR (Financial Interrelations Ratio) is regarded as a basic feature of financial development [15]. The changes reflect the changing relationship between the financial superstructure and the economic infrastructure. It is also one of the most important indicators reflecting the status and role of a country's financial structure in its national economy. The more developed the financial system, the higher the financial interrelations ratio.

The calculation formula is expressed as follows:

$$
\mathrm{FIR}=\text { bank loan/GDP }
$$

(3) Research and development (RD)

Research and development activities refer to all, organized and closely related to the generation, development, dissemination and application of scientific and technological knowledge in all fields of science and technology, namely natural sciences, agricultural sciences, medical sciences, engineering and technical sciences, humanities and social sciences. Nowadays, science and technology play a more important role in economic growth, and information and communication technology, as an important branch of science and technology, has been regarded as a major strategic emerging industry, which promotes the "third industrial revolution" and the "Internet +" pillar industries are expected to become the new engine of future economic growth. Therefore, this study takes the ratio of expenditures for research and development activities as one of the indicators to measure the degree of scientific and technological innovation.

The calculation formula is expressed as follows:

$\mathrm{RD}=$ Expenditure of Research and development/GDP

(4) Information Communications Technology (ICT)

Information and Communication Technology, referred to as ICT (Information Communications Technology). In the past, communication technology and information technology were two completely different categories: communication technology focused on the transmission technology of message dissemination, while information technology focused on the encoding or decoding of information, and the transmission method on the communication carrier. With the development of technology, these two technologies have gradually become inseparable and gradually merged into one category. In recent years, 5th generation mobile networks referred to as $5 \mathrm{G}$ has become a hot spot for discussion in the communications industry and academia. The performance goals of $5 \mathrm{G}$ are high data rates, reduced latency, energy savings, cost reduction, increased system capacity and large-scale device connections.

Therefore, it can be seen that the development of ICT (information and communication technology), as a manifestation of technological innovation capabilities, has promoted the transformation of the traditional banking industry, and has also promoted the birth of emerging industries, thereby promoting economic growth. Therefore, this study takes ICT as one of the indicators to measure the degree of technological innovation.

$$
\mathrm{ICT}=\text { total telecommunications business / GDP }
$$




\section{Empirical Results}

\subsection{Time Series Diagram}

Before performing the ADF unit root test, we need to determine the form of the test regression model. The inspection can be judged by the time series diagram of the sequence drawn by EVIEWS. There are three forms of regression, namely: 1 . None Lag length, means no intercept and no time series; 2. Intercept, means Including intercepts without time trend, the series deviates from zero, but there is no obvious time trend; 3 . trend and intercept, Used for sequences containing intercept terms and time trends, where the sequence moves significantly in one direction over time.

According to EVIEWS, a time series diagram of each variable is drawn: the series ISU, BANK, FIR, RD, and ICT contain trend and intercept. The time series diagram is as follows:

ISU

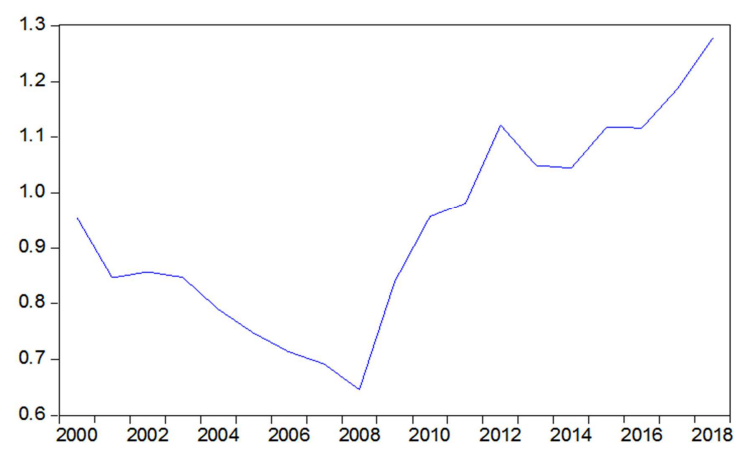

Figure 1. ISU time series diagram.

BANK

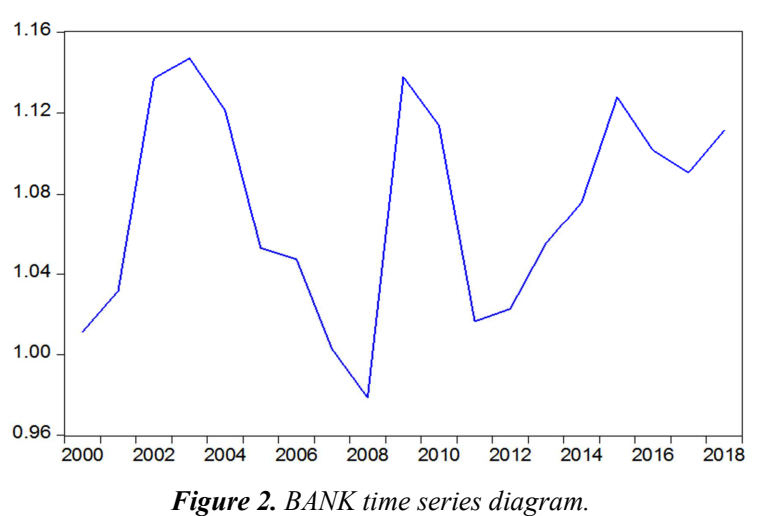

FIR

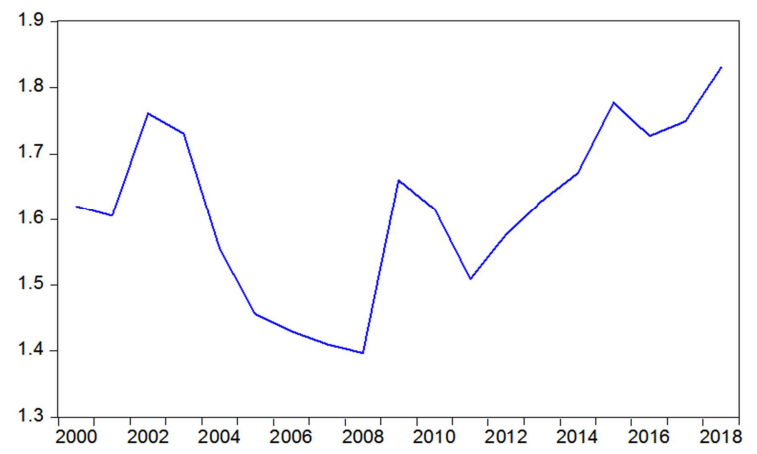

Figure 3. FIR time series diagram.
LDR

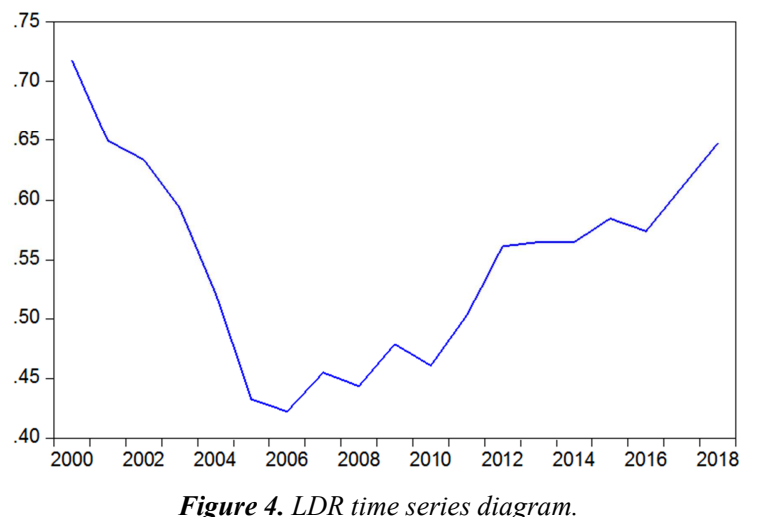

RD

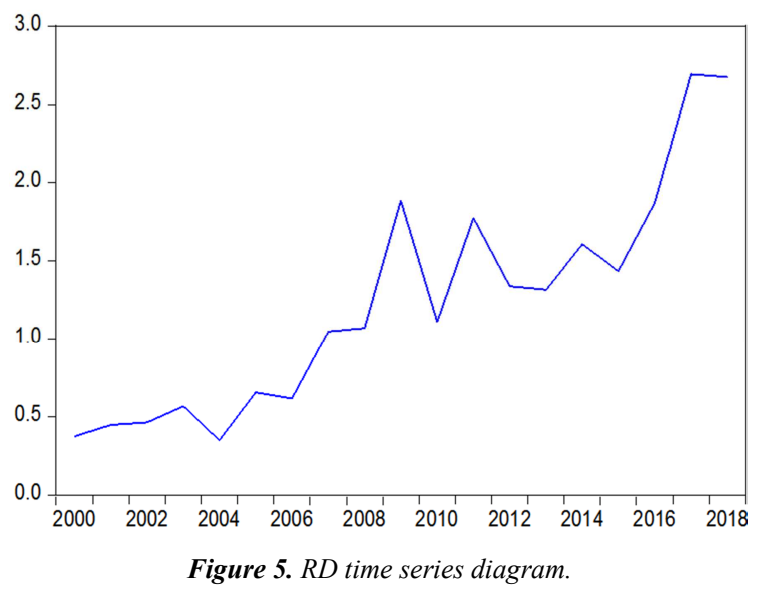

ICT

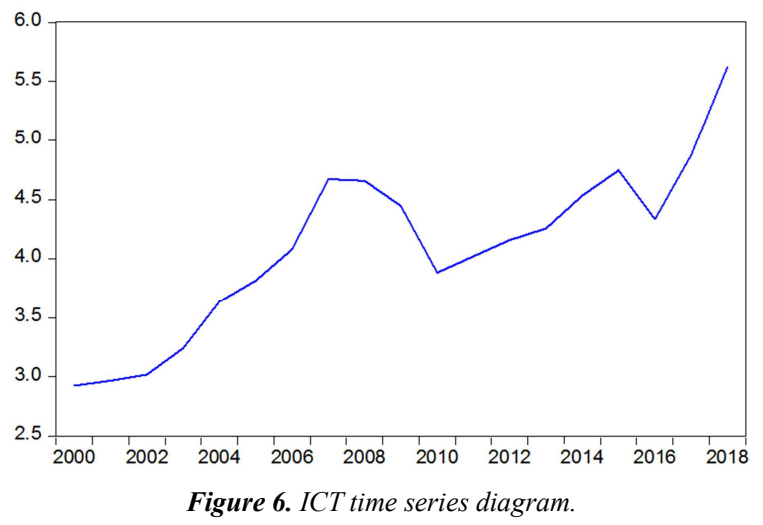

\subsection{Augmented Dickey-Fuller Test}

The unit root test is a commonly used standard method to check the stationarity of a series. Single root test is to test whether the time series contains unit roots. The most common test method is ADF test (Augmented Dickey-Fuller Test). If it contains unit roots, the time series is non-stationary.

Before performing the ADF unit root test, it is necessary to determine the form of the test regression equation model. It can be judged by drawing the sequence diagram of the sequence. The trend and intercept method is selected for single-root verification according to the change of the time 
sequence diagram of the variable. The verification results obtained are shown in Table 2:

In the Unit Root Test of ISU in the original sequence, the T statistic probability is 0.539 , which is greater than 0.1 , so the original sequence is not stable. After the first order difference, the probability of the $\mathrm{T}$ statistic is 0.037 , which is less than 0.05 , so ISU is stable after the first order difference.

In the Unit Root Test of BANK in the original sequence, the $\mathrm{T}$ statistic probability is 0.231 , which is greater than 0.1 , so the original sequence is not stable. After the first order difference, the probability of the $\mathrm{T}$ statistic is 0.002 , which is less than 0.01, so BANK is stable after the first order difference.

In the Unit Root Test of FIR in the original sequence, the T statistic probability is 0.737 , which is greater than 0.1 , so the original sequence is not stable. After the first order difference, the probability of the $\mathrm{T}$ statistic is 0.046 , which is less than 0.05 , so FIR is stable after the first order difference.

In the Unit Root Test of RD in the original sequence, the $\mathrm{T}$ statistic probability is 0.113 , which is greater than 0.1 , so the original sequence is not stable. After the first order difference, the probability of the $\mathrm{T}$ statistic is 0.000 , which is less than 0.01 , so RD is stable after the first order difference.

In the Unit Root Test of ICT in the original sequence, the T statistic probability is 0.877 , which is greater than 0.1 , so the original sequence is not stable. After the first order difference, the probability of the $\mathrm{T}$ statistic is 0.089 , which is less than 0.1 , so ICT is stable after the first order difference.

Table 2. Variable unit root test results table.

\begin{tabular}{lllll}
\hline ADF Test & $\begin{array}{l}\text { Original } \\
\text { sequence }\end{array}$ & Stationarity & $\begin{array}{l}\text { First order } \\
\text { difference }\end{array}$ & Stationarity \\
\hline ISU & 0.539 & unstable & 0.037 & steady \\
BANK & 0.231 & unstable & 0.002 & steady \\
FIR & 0.737 & unstable & 0.046 & steady \\
RD & 0.113 & unstable & 0.000 & steady \\
ICT & 0.877 & unstable & 0.089 & steady \\
\hline
\end{tabular}

\subsection{AR Roots Tests}

\section{Inverse Roots of AR Characteristic Polynomial}

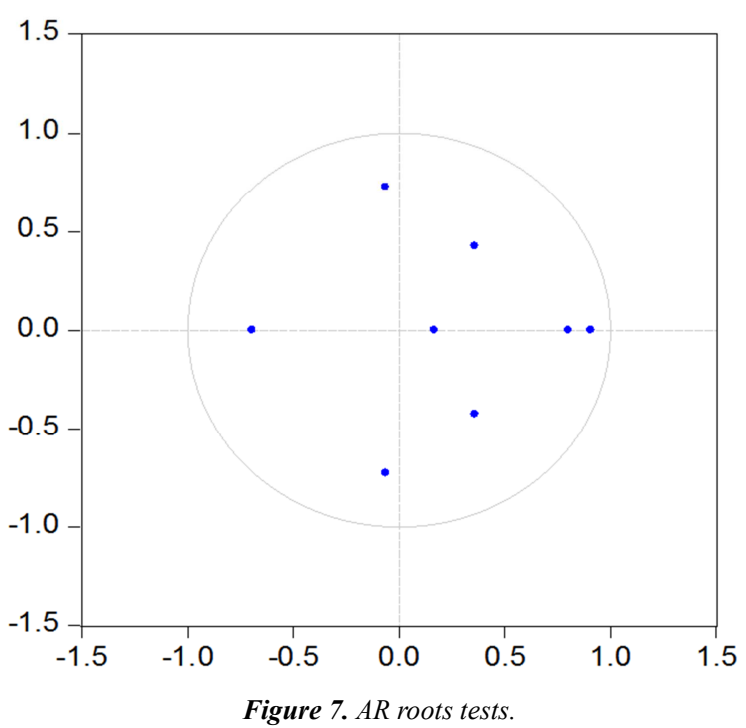

For a VAR model with a lag period of $M$ and $K$ endogenous variables, the characteristic root polynomial has $\mathrm{M} \times \mathrm{K}$ characteristic roots. When all the reciprocal modules of the characteristic roots of the VAR model are located in the unit circle (less than 1), then VAR can be considered stable. If the modulus of the reciprocal of a characteristic root is equal to 1 (located on the unit circle) or greater than 1 (located outside the unit circle), the VAR model is unstable. The characteristic root result of the research model is shown in Figure 7. It can be seen that the modulus of the reciprocal of the AR characteristic root falls within the unit circle, indicating that the VAR model established in the stationary phase is stable. The Granger causality test can be continued below.

\subsection{Q-statistics of Residual Diagnostics}

The Q-statistics of residual diagnostics is generally used to test whether the sequence has autocorrelation. The test results are shown in Figure 8. The Prob values are all greater than the set significance level, so accepting the null hypothesis, it can be considered that there is no autocorrelation in the residual sequence.

\begin{tabular}{|c|c|c|c|c|c|c|c|c|}
\hline Autocorre & ation & Partial Corre & lation & & $A C$ & PAC & Q-Stat & Prob \\
\hline 1 & 1 & 1 & 1 & 1 & 0.146 & 0.146 & 0.4496 & 0.503 \\
\hline 1 & 1 & 1 & 1 & 2 & 0.060 & 0.039 & 0.5295 & 0.767 \\
\hline 1 & I & 1 & 1 & 3 & 0.210 & 0.200 & 1.5872 & 0.662 \\
\hline $1 \square$ & 1 & I & 1 & 4. & $-0.30 \ldots$ & $-0.39 \ldots$ & 4.0343 & 0.401 \\
\hline 14 & 1 & 1 & 1 & 5 & $-0.10 \ldots$ & $-0.00 \ldots$ & 4.3576 & 0.499 \\
\hline 1 & 1 & 1 & 1 & 6 & 0.037 & 0.045 & 4.3988 & 0.623 \\
\hline 1 & 1 & 1 & 1 & 7 & 0.010 & 0.197 & 4.4020 & 0.732 \\
\hline 1 다 & 1 & । & 1 & 8 & $-0.13 \ldots$ & $-0.35 \ldots$ & 5.0951 & 0.747 \\
\hline 17 & 1 & 1 & 1 & & $-0.01 \ldots$ & 0.006 & 5.1058 & 0.825 \\
\hline 1 & 1 & 1 & 1 & $1 \ldots$ & $-0.04 \ldots$ & $-0.06 \ldots$ & 5.2124 & 0.877 \\
\hline 1 미 & 1 & I & 1 & $1 \ldots$ & $-0.16 \ldots$ & 0.100 & 6.5449 & 0.835 \\
\hline 1 & 1 & 1 다 & 1 & $1 \ldots$ & 0.032 & $-0.14 \ldots$ & 6.6048 & 0.883 \\
\hline
\end{tabular}

Figure 8. Q-statistics of residual diagnostics.

\subsection{Johansen Test}

Among the cointegration relationships among multiple variables, the Johansen cointegration test method is the most commonly used. Cointegration theory believes that even if some economic variables are non-stationary series, their linear combination may be a stationary series. This stable linear combination is called a cointegration equation to explain the long-term stable equilibrium relationship between variables. The Johansen cointegration test can obtain the estimation result of the cointegration vector while testing the number of cointegration relations.

The results of the cointegration model are shown in Table 3. The P-value of At most 2 is 0.076 , which is greater than 0.05 , indicating that ISU and BANK, FIR, RD, and ICT have long-term stable relationships. The cointegration equation is as follows:

$\mathrm{ISU}=45.887 \mathrm{BANK}-22.766 \mathrm{FIR}+3.921 \mathrm{RD}-3.518 \mathrm{ICT}$ 
Through the co-integration equation, it can be known that BANK and ISU have a positive correlation in the long-term stable relationship. For every $1 \%$ increase in BANK, the GDP will increase by $45.887 \%$. FIR and ISU are negatively correlated. For every $1 \%$ increase in FIR, ISU decreases by $22.766 \%$. There is a positive correlation between RD and ISU. For every $1 \%$ increase in RD, GDP increases by $3.921 \%$. There is a negative correlation between ICT and GDP. For every $1 \%$ increase in ICT, ISU decreases by $3.518 \%$.

Table 3. Johansen Test results table.

\begin{tabular}{lllll}
\hline $\begin{array}{l}\text { Hypothesized } \\
\text { No. of CE (s) }\end{array}$ & Eigenvalue & $\begin{array}{l}\text { Trace } \\
\text { Statistic }\end{array}$ & $\begin{array}{l}\mathbf{0 . 0 5} \text { Critical } \\
\text { Value }\end{array}$ & Prob \\
\hline None* & 0.963 & 112.211 & 69.818 & 0.000 \\
At most 1* & 0.803 & 55.843 & 47.856 & 0.007 \\
At most 2 & 0.613 & 28.139 & 29.797 & 0.076 \\
At most 3 & 0.405 & 11.967 & 15.494 & 0.158 \\
At most 4 & 0.167 & 3.113 & 3.841 & 0.077 \\
\hline
\end{tabular}

\subsection{Granger Causality}

Table 4 shows the Granger causality between ISU and BANK, FIR, RD, and ICT. It can be seen from Table 4 that DRD and DISU are mutually Ranger causality; DICT is Granger causality of DISU; DISU has no Granger causality relationship with DBANK and DFIR.

Table 4. Granger Causality Table.

\begin{tabular}{lll}
\hline Null Hypothesis: & F-Statistic & Prob. \\
\hline DBANK does not Granger Cause DISU & 0.934 & 0.419 \\
DISU does not Granger Cause DBANK & 2.041 & 0.172 \\
DFIR does not Granger Cause DISU & 1.452 & 0.272 \\
DISU does not Granger Cause DFIR & 0.463 & 0.640 \\
DRD does not Granger Cause DISU & 4.444 & 0.035 \\
DISU does not Granger Cause DRD & 5.730 & 0.017 \\
DICT does not Granger Cause DISU & 3.168 & 0.078 \\
DISU does not Granger Cause ICT & 2.094 & 0.165 \\
\hline
\end{tabular}

\section{Conclusion}

From the empirical results, it can be seen that there is no Granger causality between BANK and ISU, which showing a positive influence; FIR and ISU have no Granger causality, which showing a negative influence; RD and ISU are Granger causality with each other, which showing a positive influence Impact; ICT is the Granger causality of ISU and has a negative impact. Research shows that the ban-based financial system has not had a positive impact on Zhanjiang's industrial structure optimization. This is because Zhanjiang's financial system has serious financial repression, state-owned commercial banks are in a monopoly position, and the market is in a state of imperfect competition. The monopolistic behavior of commercial banks will lead to inefficient operation of banks, the lack of credit systems and the accumulation of financial risks, and more serious, it will cause discrimination in credit rationing, which is not conducive to the development of small and medium-sized enterprises and hinders the deepening of financial reforms.

On the other hand, empirical evidence shows that education and technology can promote the optimization and upgrading of Zhanjiang's industrial structure. In the context of building an innovative country, the simultaneous advancement of technological innovation and financial development has become the source of power for my country's economic development [16]. From the perspective of industrial competition, a major source of changes in industrial structure is various types of technological innovation and product innovation. Technological innovation can affect the scale of industrial economy, and the diffusion of proprietary knowledge will affect the competitive advantage of the industry.

According to the empirical results, in view of the status quo of the upgrading of industrial institutions in Zhanjiang City, financial development should: 1. Lower the loan barriers to private enterprises, eliminate financing discrimination against private SMEs, and improve the level and quality of private enterprises' financial services. 2. It is necessary to innovate financial tools, optimize the financial structure, and achieve continuous improvement in the level of financial development [17]. 3. It is necessary to promote the development of Internet finance and financial technology to realize the integrated development of finance and technology. In terms of technological innovation, we should: 1. Increase investment in technological innovation, optimize the technological innovation environment, and use technological innovation as an intermediary effect to promote the effective upgrade of the industrial structure, and ultimately achieve the coordinated development of "finance, technology, and industry". 2. Zhanjiang City can establish ways and paths to combine technological innovation and financial development, and encourage relevant financial platforms to formulate relevant preferential policies including deposit support, tax reduction, and fiscal subsidies.

\section{Acknowledgements}

This paper was supported by 2019 Philosophy and Social Science planning funded project of Zhanjiang City (Grant Number: ZJ19QN03); 2019 Guangdong Coastal Economic Belt Development Research Center of Lingnan Normal University (Grant Number: 20194L02); And Humanities and Social Sciences Research Project of Lingnan Normal University (Grant Number: ZW2026).

\section{References}

[1] Xie and, Zhao. New technological innovation, financial development and industrial structure upgrading - An analysis based on Bayesian quantile regression [J]. Science and Technology Management Research, 2017, 5: 1-8.

[2] $\mathrm{Wu}$, Zhang and He Jianfeng. Research on the Coordinated Development of Financial Development, Technological Innovation and Industrial Structure Upgrade [J]. Science Technology and Economy, 2017, 5: 96-100.

[3] Thangavelu S M, Jiunn A B, James. Financial development and economic growth in Australia: An empirical analysis [J]. Empirical Economics, 2004, 29 (2): 247-260. 
[4] Shah, S. Z. A., \& Bhutta, N. T. Does financial deepening create financial crises? [J]. Journal of Emerging Trends in Economics and Management Sciences, 2014, 5 (7): 115-120.

[5] Demir, A, D., \& Hall, S, G. Financial structure and economic development: Evidence on the view of "new structuralism". [J]International Review of Financial Analysis, 2017, (52): 252-259.

[6] Hong J P. Causal relationship between ICT R\&D investment and economic growth in Korea [J]. Technological forecasting and social change, 2017, (116): 70-75.

[7] Pradhan R P, Arvin M B, Bahmani S. Are innovation and financial development causative factors in economic growth? Evidence from a panel granger causality test $[\mathrm{J}]$. Technological Forecasting \& Social Change, 2018 (132) 130-142.

[8] Grant D, Yeo B J. A global perspective on tech investment, financing, and ICT on manufacturing and service industry performance $[\mathrm{J}]$. International Journal of Information Management, 2018 (43) 130-145.

[9] Xiongfeng, $\mathrm{P}$, et al. Dynamics of financial development, trade openness, technological innovation and energy intensity: Evidence from Bangladesh [J]. Energy, 2019 (171) 456-464.

[10] Qian, Zheng and Yu Dianfan. The Impact of China's Industrial Structure Changes on Economic Growth and Volatility [J]. Economic Research, 2011, (5): 4-31.
[11] Liu. Industrial Economics [M]. Tsinghua University Press: Beijing, 2012: 129.

[12] Yu. The economic growth effect of industrial structure adjustment and productivity improvement: An analysis based on the dynamic spatial panel model of Chinese cities [J]. China Industrial Economics, 2015, 12: 83-98.

[13] Cao and Zhang. Research on the Impact of Industrial Structure Changes on Economic Growth-Taking Wuxi City as an Example [J]. Productivity Research, 2016, 2: 39-43.

[14] King, R. G., \& Levine, R. Finance and growth: Schumpeter might be right [J]. Quarterly Journal of Economic, 1993 (108): 717-738.

[15] Goldsmith, R. W. Financial structure and development [M]. Yale University Press: Britain, 1969.

[16] Feng, Liu and, Luo. Research on the Coupling of Science and Technology Innovation and Financial Development in Guangdong Province [J]. Journal of Guangzhou University, 2017, 016 (012): 63-69.

[17] $\mathrm{Wu}$, Zhang and, He. Research on the Coordinated Development of Financial Development, Technological Innovation and Industrial Structure Upgrade [J]. Science Technology and Economy, 2017 (5): 96-100. 